DOI: 10.12957/demetra.2016.22501

\title{
Eu tenho um corpo gordo, e agora? Relatos de mulheres obesas que participaram de uma intervenção não prescritiva, multidisciplinar e baseada na abordagem "Health atEverySize ${ }^{\circledR} "$
}

\section{I have a fat body, what now? Experiences of obese women following a multidisciplinary, non-prescriptive intervention, based on the Health at Every Size ${ }^{\circledR}$ approach}

\author{
Mariana D. Ulian' \\ Bruno Gualano² \\ Fabiana B. Benatti \\ Patricia L. de Campos-Ferraz ${ }^{3}$ \\ Odilon J. Roble ${ }^{4}$ \\ Bruno T. Modesto ${ }^{2}$ \\ Gabriel T. de Medeiros ${ }^{5}$ \\ Ramiro F. Unsain ${ }^{6}$ \\ Priscila de M. Sato \\ Ana Carolina Machado Poppe \\ Fernanda B. Scagliusi \\ 1 Universidade de São Paulo, Faculdade de Saúde \\ Pública. São Paulo-SP, Brasil. \\ ${ }^{2}$ Universidade de São Paulo, Escola de Educação \\ Física e Esporte. São Paulo-SP, Brasil. \\ ${ }^{3}$ Universidade de Campinas, Faculdade de \\ Ciências Aplicadas. Limeira-SP, Brasil. \\ ${ }^{4}$ Universidade de Campinas, Faculdade de \\ Educação Física. Campinas-SP, Brasil. \\ ${ }^{5}$ Universidade de São Paulo, Instituto de \\ Psicologia. São Paulo-SP, Brasil. \\ ${ }^{6}$ Universidade Federal de São Paulo, Instituto de \\ Saúde e Sociedade. Santos-SP, Brasil. \\ Correspondência / Correspondence \\ Mariana Dimitrov Ulian \\ Departamento de Nutrição, Faculdade de Saúde \\ Pública da Universidade de São Paulo - Av. Dr. \\ Arnaldo, 715, São Paulo, SP, CEP: 01246-904, \\ Brasil. \\ E-mail:m.dimitrov@usp.br.
}

\section{Resumo}

Objetivou-se analisar qualitativamente a percepção de mulheres obesas sobre ter um corpo gordo e como elas vivenciaram e foram impactadas por essa condição corporal antes e depois de participarem de uma intervenção não prescritiva, multidisciplinar e baseada na abordagem "Health atEverySize ${ }^{\circledR ”}$. Trata-se de ensaio clínico prospectivo, quasi-experimental, com um ano de duração. Os dados qualitativos foram coletados por meio da condução de três grupos focais e de entrevistas individuais semiestruturadas. Inicialmente, 30 participantes foram recrutadas; 14 concluíram a intervenção. A partir dos dados dos grupos focais e das entrevistas individuais, três eixos interpretativos foram criados: 1) impactos do corpo gordo; 2) opiniões sobre o próprio corpo e a docilidade do corpo gordo; e 3) movimentação do corpo. As participantes relataram que o corpo gordo impactou na construção de aspectos da sua personalidade, diminuindo, por exemplo, possibilidades de vínculos e interações sociais. A partir dos estímulos da intervenção proposta, segundo as percepções das participantes, tais aspectos foram positivamente afetados. Elas também relataram ter sofrido experiências de assédio moral e discriminação por causa de seus corpos. A partir da exposição às estratégias desta intervenção, as participantes relataram se sentir mais empoderadas para lidar com expectativas acerca de seus corpos e mais confortáveis com sua condição corporal atual. Por fim, relataram transitar de experiências negativas associadas à movimentação do corpo para experiências positivas com as mesmas, motivando-as a inserir mais atividades físicas em suas rotinas, além de proporcionar ganhos fisiológicos e psicológicos.

Palavras-chave: Obesidade. Estilo de Vida. Promoção da Saúde. Health at Every Size. Imagem Corporal. Análise Qualitativa. 


\section{Abstract}

The present study qualitatively analyzed the perception of obese women on having a fat body and how they experienced and were impacted by this body condition before and after participating in a non-prescriptive, multidisciplinary intervention, based on the Health at Every Size ${ }^{\circledast}$ approach. A prospective 1-year quasi-experimental clinical trial was conducted. Initially, 30 participants were recruited; 14 concluded the intervention. Qualitative data were collected by conducting focus groups and semi-structured individual interviews. From these data, three interpretative axes were created: 1) impact of the fat body; 2) opinions on the body itself and the docility of the fat body and; 3) movement of the body. Our participants reported that the fat body had an impact on the construction of aspects of their personality, reducing, for example, possibilities of bonding and social interactions. Based on the proposed intervention stimuli, according to the perceptions of the participants, these aspects were positively affected. The participants also reported having suffered bullying and discrimination because of their bodies. After exposure to the strategies of this intervention, participants reported feeling more empowered to deal with expectations about their bodies and more comfortable with their current body condition. Finally, participants reported shifting from negative experiences associated with body movement to positive experiences, thus feeling motivated to add more physical activity into their routines, besides gaining physiological and psychological benefits.

Key words: Obesity. Non-Prescriptive Intervention. Health at Every Size. Body Image. Qualitative Inquiry.

\section{Introdução}

Construções relacionadas ao corpo são maleáveis e moldadas por esferas culturais, sociais, organizacionais, profissionais e individuais. O corpo pode ser entendido como um atributo relacionado à cultura, refletindo normas e significados específicos de determinado contexto cultural. ${ }^{1,2}$ Por exemplo, o corpo magro não fora sempre o modelo de saúde (e beleza) e a construção do discurso de saúde acerca do corpo gordo é relativamente recente.

É a partir do Renascimento que a beleza feminina passa a ser socialmente reconhecida como um preditor de caráter moral que deve ser externalizado. Nos séculos XVI e XVII, a gordura, tanto corporal quanto na alimentação, era percebida como saudável e sinal de status social. ${ }^{3}$ Das 
mulheres, era esperado que fossem volumosas; o corpo roliço, com quadris grandes e abdome avantajado, eram atributos que sinalizavam culturalmente fertilidade, boa saúde, estabilidade emocional e status social., ${ }^{4,5}$

É apenas no final do século XVIII que há uma mudança na percepção da gordura, e corpos menores começam a ser associados a atributos desejáveis a mulheres, como delicadeza e bondade. ${ }^{3}$ Também assume-se que o medo de engordar seja uma preocupação predominantemente feminina, sendo a prática de dietas de emagrecimento automaticamente associada às mulheres. ${ }^{6}$ No entanto, em meados de 1800, no mundo ocidental, as recomendações de controle do corpo visavam ao público masculino. Para estes, o corpo esbelto representaria maior influência, poder político e privilégios sociais.

Nesse contexto, a medicina começou a se preocupar com a obesidade, mas o aumento de apetite e a proporcionalidade dos volumes corporais eram, ainda, mais importantes do que, precisamente, o tamanho do corpo. Ainda não existiam padrões específicos para determinar a obesidade, sendo esta definida por parâmetros estritamente estéticos. Não era o sujeito que se classificava doente, mas o outro, através da comparação a um padrão socialmente reconhecido de beleza. Aquém de um padrão de normalidade, que era possível apenas com a medicina quantitativa e ainda inexistente, o reconhecimento da obesidade residia na capacidade do médico de identificar o natural e o não natural. ${ }^{7}$

Com o surgimento da racionalidade científica, saber e poder tornaram-se entrelaçados, pois saber implicava a detenção de poder sobre os homens, ${ }^{8}$ investindo na quantificação como meio para o desenvolvimento da noção de saúde ancorada na normalidade. ${ }^{9}$ Assim, os enunciados de Flemyng (1760, apud..$\left.^{7}\right)$ e de Brown (1788, apud. ${ }^{7}$ ) contrastavam com as definições anteriores, pela substituição de conotações estéticas por um discurso biopatologizante, buscando estirpar-lhe todo o ranço de questões estéticas ou morais. ${ }^{7}$

Sob tal prisma, pode-se constatar que a patologização do corpo gordo ocorreu por meio de um processo contínuo, cultural e historicamente datado. ${ }^{7,10} \mathrm{Com}$ essa mudança na expectativa do corpo, para o público feminino, a dieta restritiva se tornou uma prática popular por volta do ano de 1920. A pressão social para que as mulheres seguissem o novo ideal de beleza crescia, ao mesmo tempo que as mensagens negativas endereçadas ao corpo com excesso de peso aumentavam, relacionando tal condição física à imoralidade, falta de controle e de disciplina. ${ }^{11}$

A disciplina nutricional e o controle do corpo passaram a ser vistos como meios para as mulheres alcançarem influências e privilégios iguais aos dos homens. Assim, a dieta pode ser vista como uma prática multifacetada, que não apenas sujeita o corpo a normas culturais, mas simultaneamente permite a indivíduos privilégios e direitos. ${ }^{11}$ A dieta se tornou uma questão moral, envolvendo a capacidade individual de controle, podendo resultar em privação e depleção de energia física e emocional. ${ }^{12,13}$ 
Para muitas pessoas, especialmente as mulheres, o gerenciamento do peso corporal se tornou um projeto contínuo. ${ }^{14}$ De acordo com a pesquisa mais recente do National Health and Nutrition Examination Survey (NHANES), conduzida entre 2003 e 2008, três em cinco cidadãos americanos desejavam perder peso, e $57 \%$ das mulheres e $40 \%$ dos homens tinham se engajado em algum tipo de dieta no ano anterior. ${ }^{15}$

Atualmente, de acordo com pesquisas na Europa e América do Norte, é estimado que de 25 a $65 \%$ das mulheres e de 10 a $40 \%$ dos homens se engaje em alguma dieta visando à perda de peso. ${ }^{16}$ No entanto, evidências vêm mostrando que esta é sustentada por apenas pequena parcela das pessoas e muitos ganham ainda mais peso do que antes da dieta ${ }^{17-19}$.

Siahpush et al. ${ }^{19}$ examinaram longitudinalmente a associação entre fazer dieta com o peso corporal e o índice de massa corporal (IMC). Aqueles que fizeram dieta uma vez, mais de uma vez e sempre, quando comparados com aqueles não fizeram dieta tiveram, respectivamente, chances 1,9; 2,9 e 3,2 vezes maiores de desenvolver obesidade. Desta forma, o interesse por outras estratégias de cuidado se mostra fundamental e tem ganhado espaço.

As outras estratégias de cuidado diferem das intervenções tradicionais voltadas para pessoas gordas, uma vez que focam na aceitação corporal, emocional e individual como meios para melhorar a saúde física e emocional de tais pessoas (quando e se necessário), sem focar no controle de peso corporal. ${ }^{20}$ Entre elas, destaca-se a abordagem "Health at EverySize" ${ }^{\circledR}\left(\mathrm{HAES}^{\circledR}\right)$, nome cunhado pela Association for Size Diversity and Health (ASDAH 201320).

O HAES ${ }^{\circledast}$ tem como objetivo encorajar comportamentos saudáveis para pessoas de todos os tamanhos corporais, sendo a perda de peso corporal uma consequência ou não desse processo. Seus princípios incluem: 1) reconhecer que a saúde e bem-estar são multidimensionais e incluem aspectos emocionais, físicos, espirituais e intelectuais; 2) encorajar a construção de uma imagem corporal positiva; 3) aceitar e respeitar a diversidade de tamanhos e formatos corporais; 4) promover uma alimentação que equilibre necessidades nutricionais individuais, além de aspectos como fome, saciedade, apetite e prazer; e 5) promover atividades físicas prazerosas e sustentáveis. ${ }^{20}$

Provencher et al. ${ }^{21}$ e Gagnon-Girouard et al. ${ }^{22}$ verificaram o impacto de uma intervenção baseada na abordagem HAES ${ }^{\circledR}$ em variáveis psicológicas e no peso corporal de mulheres com sobrepeso e obesidade. Esta teve quatro meses de duração e as participantes foram aleatoriamente distribuídas em três grupos: HAES ${ }^{\circledR}$; apoio social e lista de espera. No grupo HAES ${ }^{\circledR}$, palestras foram conduzidas a fim de aumentar a atenção e conhecimento das participantes sobre aspectos biopsicossociais que envolvem a saúde e peso corporal. O grupo de apoio social teve o mesmo formato que o primeiro, mas as participantes não foram orientadas e as discussões não eram direcionadas. O último grupo foi orientado a manter seus hábitos usuais e não teve contado com o grupo de pesquisa; no final do período de acompanhamento, este recebeu a mesma orientação que o grupo HAES ${ }^{\circledR}$. 
Todos os grupos apresentaram melhoras durante a intervenção, que se relacionaram a mudanças na qualidade de vida, insatisfação corporal e compulsão alimentar, avaliadas por meio de questionários e analisadas estatisticamente. No entanto, apenas o grupo HAES $®$ as mantiveram durante o período de acompanhamento e somente neste grupo a manutenção de peso corporal nos 12 meses de seguimento se relacionou com as melhoras psicológicas resultantes da intervenção.

Em longo prazo, as mudanças do grupo $\mathrm{HAES}^{\circledR}$ foram mantidas ou continuaram melhorando, o que não aconteceu nos outros grupos. Borkoles et al. ${ }^{23}$ propuseram uma intervenção baseada na abordagem HAES ${ }^{\circledast}$ para uma população de mulheres com obesidade grau III. As participantes foram submetidas a três meses de intervenção, seguidos por nove meses de acompanhamento. A intervenção teve como estratégias abordagens voltadas para a prática de atividade física e mudanças no comportamento alimentar, e o grupo controle foi orientado a manter seus hábitos atuais. Observaram-se mudanças modestas, embora estatisticamente significantes, no peso corporal das participantes do grupo intervenção. Ao longo do período de acompanhamento, não foram observadas mudanças posteriores nesta variável, mas as participantes do grupo intervenção apresentaram melhora significativa em variáveis psicológicas e no comportamento sedentário, diferentemente do grupo controle.

Os estudos têm mostrado que as intervenções baseadas no HAES ${ }^{\circledR}$ parecem melhorar aspectos como autoestima, insatisfação corporal, comportamento alimentar e composição corporal ${ }^{21,22,24-28}$. Embora um dos princípios do $\mathrm{HAES}^{\oplus}$ seja encorajar a construção de uma imagem corporal positiva, não foram encontradas intervenções que avaliaram as percepções dos participantes acerca de sua condição corporal depois de inseridos em intervenções baseadas nessa abordagem. Considerando a construção histórica do corpo como preditor de caráter moral e do fortalecimento da racionalidade científica para classificar o corpo, essa investigação se mostra importante, pois traz a perspectiva desses indivíduos cujos corpos são frequentemente classificados e patologizados pelo olhar do outro, seja este estético ou fisiopatológico.

O objetivo deste artigo é analisar, qualitativamente, a percepção de mulheres obesas sobre ter um corpo gordo e como elas vivenciaram e foram impactadas por essa condição corporal antes e depois de participarem de uma intervenção não prescritiva, multidisciplinar e baseada na abordagem "Health at Every Size ${ }^{\circledR}$.

\section{Métodos}

Desenho do estudo e participantes

Este foi um ensaio clínico prospectivo, quasi-experimental, que teve um ano de duração. Foram selecionadas 30 mulheres, participantes da intervenção "Saúde e bem-estar na obesidade", cujo 
desenho e resultados principais já foram descritos por Ulian e colaboradores. ${ }^{29-32}$ Os critérios de inclusão eram: a) ser do sexo feminino; b) ter idade entre 25 e 50 anos; c) ter um IMC acima de $30 \mathrm{~kg} / \mathrm{m}^{2}$; d) ser alfabetizada; e) não ter diabetes mellitus 1 e 2; f) não realizar acompanhamento nutricional fora da intervenção; g) não usar remédios para emagrecimento. Das 30 participantes selecionadas inicialmente, 14 concluíram a intervenção.

Todas assinaram o Termo de Consentimento Livre e Esclarecido. O projeto foi aprovado pelo Comitê de Ética da Universidade Federal de São Paulo e o estudo foi registrado no clinicaltrials. gov sob o registro NCT02102061.

\section{Características da intervenção}

A intervenção consistia em atividades físicas três vezes por semana (por uma hora), oficinas filosóficas, no total de cinco ao longo da intervenção, e atendimentos nutricionais individuais quinzenais. Quadrimestralmente, eram feitos grupos focais, exames de sangue, avaliações antropométricas e preenchimento de escalas e questionários autoaplicados.

As atividades físicas incluíram atividades lúdicas em circuito, com enfoque no desenvolvimento de capacidades aeróbia e anaeróbia, força, propriocepção e flexibilidade. Nas oficinas, foram debatidos temas que encontram discussão na filosofia e fazem parte do universo que envolve a questão da obesidade. Entre os temas, pode-se citar o mecanismo de desejo e tédio, restrição e saúde, moralização do corpo e da saúde, liberdade e ansiedade.

A intervenção nutricional se fundamentou no aconselhamento nutricional. Trata-se de "um encontro entre duas pessoas para examinar com atenção, olhar com respeito, e deliberar com prudência e justeza sobre a alimentação de uma delas". ${ }^{33}$ Destacam-se como principais estratégias utilizadas durante o aconselhamento nutricional: o automonitoramento, o estabelecimento de metas e o planejamento alimentar. $\mathrm{O}$ automonitoramento foi realizado por meio de um registro diário do consumo alimentar. Este inclui anotações sobre o horário, local, companhia e duração das refeições, sentimentos e pensamentos relacionados, se foi um consumo planejado, prazeroso, e as notas de fome e saciedade.

A partir do diário, percebia-se o que precisava ser trabalhado em ordem de importância e urgência, e fazia-se o planejamento alimentar. De maneira simplificada, este foi utilizado para auxiliar as participantes a planejarem quais e a quantidade de alimentos mais adequados para serem consumidos. Ademais, as nutricionistas buscaram aumentar a atenção das participantes para os sinais de fome e saciedade; para os gatilhos emocionais ou ambientais que poderiam levar a comportamentos alimentares automáticos e estimulá-las a construir uma rede de apoio externa à intervenção. Os atendimentos nutricionais individuais tiveram 45 minutos de duração. 


\section{Coleta de dados e análise}

Um antropólogo experiente conduziu três grupos focais ao longo da intervenção. Além dele, uma observadora anotava expressões, gestos e outras marcas não verbais das participantes. Ambos eram membros da equipe de pesquisa, porém não da de intervenção.

Cada grupo teve um roteiro de perguntas, elaboradas por todos os profissionais da intervenção. Tais roteiros não foram pré-testados e foram diferentes em cada grupo focal, pois algumas atividades e reflexões foram inseridas em diferentes momentos ao longo da intervenção e, por isso, não se adequariam caso fossem abordadas em todos os grupos focais. Nesse sentido, algumas questões iniciais não se adequariam se questionadas ao final da intervenção e vice-versa. Com roteiros de perguntas diferentes em cada grupo focal, foi possível observar a evolução da intervenção e das participantes, além de permitir mudanças nas estratégias utilizadas, quando necessário.

Embora as discussões dos grupos focais tenham contemplado todas as áreas envolvidas, o presente artigo analisará aquelas que se referem a relatos sobre o corpo. As participantes eram convidadas a participar dos grupos focais. O convite era feito pessoal e individualmente, e era um momento no qual o objetivo dos encontros era explicado. Esperavam-se de sete a oito mulheres para compor os grupos focais, porém, prevendo faltas, dez eram convidadas, exceto no último, no qual todas foram incluídas. Cada grupo focal contou com a participação de sete mulheres.

A amostragem foi feita da seguinte maneira: no primeiro grupo focal, uma vez que a intervenção contava com um número maior de participantes, foi feito um sorteio para garantir que os convites seriam feitos aleatoriamente. No segundo, as mulheres presentes no primeiro grupo foram reconvidadas e novos convites, também estabelecidos por meio de sorteio, foram estendidos a outras participantes. No último grupo focal, as participantes do primeiro e segundo grupos focais também foram reconvidadas. Uma delas havia desistido da intervenção e, dessa forma, devido às desistências, apenas uma participante não seria incluída, por não ter participado de nenhum grupo; por isso, esta também foi convidada.

Considerando os três grupos focais conduzidos, 12 das 14 participantes estiveram presentes neles. Destas, duas participaram dos três grupos focais, cinco de dois, e cinco de um grupo focal. O tempo de duração dos encontros variou de 80 a 100 minutos. Todos foram gravados por dois gravadores digitais e transcritos por um membro da equipe de pesquisa. Nas transcrições, as anotações da observadora foram incluídas, embora não tenham composto a análise final. Pretendiase, com elas, que a equipe observasse o andamento dos grupos e o engajamento das participantes nos mesmos. A análise dos dados coletados nos grupos focais foi devolvida para as participantes ao final da intervenção. 
Além dos grupos focais, um pesquisador integrante da intervenção conduziu entrevistas individuais com todas as participantes no início da intervenção. As entrevistas tiveram como objetivo investigar a trajetória de vida e como as participantes compreendiam e desenvolveram práticas alimentares e corporais. Foi solicitado que as mesmas relatassem hábitos passados e atuais abrangendo tais temas, bem como que refletissem sobre sua trajetória de vida. As participantes foram encorajadas a reconhecer momentos marcantes, de cunho individual ou coletivo, além de mudanças no seu estilo de vida e de sua estrutura familiar. O tempo de duração dos encontros variou de 60 a 120 minutos.

As entrevistas foram gravadas por dois gravadores digitais e transcritas. Posteriormente, narrativas de história de vida foram construídas por meio da estruturação dos relatos de cada participante, cuidando para atribuir ênfase a sua percepção histórica de construção de hábitos de vida, suas influências culturais e familiares, e a identificação de símbolos, valores, crenças e comportamentos envolvidos, de acordo com os referenciais teóricos e metodológicos de Lima \& Gualda, ${ }^{34}$ Paulilo ${ }^{35}$ e Thompson. ${ }^{36}$ Após essa fase, as narrativas foram devolvidas às participantes, para que pudessem sugerir mudanças às mesmas, caso sentissem necessidade. Das 14 participantes que concluíram a intervenção, oito deram consentimento para utilização de suas histórias de vida.

A partir dos dados dos grupos focais e das entrevistas individuais, foram feitas leituras atentas dos materiais transcritos. Durante esse processo, elementos importantes presentes em cada relato eram destacados e reflexões acerca dos mesmos eram anotadas separadamente. Posteriormente, elementos semelhantes, complementares ou que remetiam a uma mesma categoria foram organizados em eixos interpretativos, os quais não foram estabelecidos de antemão, e sim nomeados de acordo com o sentido brotado. Esses eixos interpretativos serão apresentados na seção de resultados e discussão e serão articulados com os referenciais teóricos da literatura sobre o HAES® e sobre as abordagens não prescritivas. A fim de preservar o anonimato das participantes, elas estão identificadas como participante (P).

\section{Resultados e Discussão}

A tabela 1 ilustra as características demográficas das participantes. Das 30 participantes que iniciaram a intervenção, 16 se desligaram antes do fim da mesma. Três mudaram de cidade, três não tinham disponibilidade de tempo, uma ficou grávida, quatro alegaram motivos pessoais e cinco, motivos de saúde. Os eixos interpretativos construídos a partir dos grupos focais e das entrevistas individuais estão apresentados a seguir. 
Tabela 1. Características gerais das participantes de uma intervenção multidisciplinar, não prescritiva e baseada na abordagem "Health atEverySize”( $\left.{ }^{\circledR}=14\right)$.São Paulo, 2013.

\begin{tabular}{lll}
\hline Característica & Média (Desvio-padrão) & $\%$ \\
Idade (anos) & $45(7,1)$ & \\
\hline
\end{tabular}

Educação

Ensino Médio completo

28,6

Ensino Superior completo $\quad 71,4$

História do ganho de peso

Infância

Adolescência

Idade adulta

Ocupação

Professora

Dona de casa/aposentada

Estudante

Trabalhadora autônoma

14,3

Funcionária pública

7,2

Trabalhadora terceirizada

21,4

Estado civil

Solteira

Casada

Divorciada

14,3

Viúva 


\section{Impactos do corpo gordo}

Impactos psicológicos para aqueles que têm um corpo gordo podem ser construídos por processos físicos e sociais. ${ }^{37}$ Aspectos sociais incluem mensagens negativas sobre ter um corpo gordo, que, quando expressas sistematicamente, se refletem na construção de ambientes e discursos que discriminam e não toleram esse corpo. Estes são evidentes em instituições e nas falas cotidianas, resultando em discriminação e estigmatização daqueles que têm um corpo gordo. ${ }^{37}$

Em sua obra, Goffman ${ }^{38}$ descreve a estigmatização como um processo que tende a desacreditar um indivíduo considerado "desviante". Segundo o autor, a estigmatização é o resultado de interações sociais que rotulam o "desviante" como aquele que se afasta dos que são, supostamente, considerados "normais". Uma vez atribuída, a característica estigmatizadora justifica uma série de descriminações sociais ou exclusões mais ou menos severas.

Goffman ${ }^{38}$ propõe também a ideia de status principal para refletir a redução de um indivíduo à característica-alvo da estigmatização, ficando com outras qualidades em segundo plano. É por isso que as pessoas obesas são frequentemente caracterizadas por seu peso do que por outros atributos sociais ou pessoais. ${ }^{38}$ Em adição aos problemas psicológicos decorrentes de comportamentos discriminatórios e estigmatizantes, estes também parecem ter implicações na manutenção do peso corporal.

Em um estudo longitudinal, observou-se que participantes que sofreram discriminação por causa do peso corporal eram aproximadamente 2,5 vezes mais propensos a se tornar obesos, e aqueles que eram obesos e sofreram discriminação tinham três vezes mais chance de se manter obesos quando comparados com pessoas que não haviam sido discriminadas. ${ }^{39}$

Nossas participantes relataram impactos relacionados a sua condição corporal. Algumas trouxeram relatos da época da infância ou adolescência. Em uma das entrevistas de histórias de vida, a participante levantou uma transição de personalidade dela. Enquanto que na infância ela se considerava uma criança extrovertida, na adolescência, experiências negativas relacionadas a sua condição corporal fizeram com que houvesse uma mudança nessa característica. Ela relatou que passou a ser mais introvertida e a ter menos interesse em participar de situações sociais:

Lembro na infância de ser muito mais extrovertida do que sou hoje. Na adolescência eu sinto que essa extroversão eu fui perdendo no caminho, um pouco devido à obesidade. [...] Eu lembro que o meu apelido na escola era "gordinha". Na época eu engoli isso e eu não cheguei a verbalizar isso em casa, mas aquilo por dentro me machucava. (P1). 
Outra participante levantou que, por ser uma adolescente obesa, ela tinha dificuldade com relacionamentos amorosos. Como alternativa, voltou-se para atividades individuais:

Entre os 12, 15 anos acho que eu era bastante gordinha e com bastante dificuldade no campo de relacionamentos, então todas as meninas namoravam, e eu, gordinha, não namorava. Mas sempre fui bastante interessada em leitura, em música, então sempre encontrei na arte um refúgio para viver bem. (P10).

Impactos do corpo gordo nesses ciclos da vida também puderam ser observados no estudo de Puhl \& Luedicke. ${ }^{40}$ Os autores observaram que estudantes do ensino médio que reportaram ter emoções negativas devido ao assédio sofrido pelo excesso de peso eram mais propensos a evitar atividades físicas e também respondiam a esse confronto aumentando o consumo alimentar. ${ }^{40}$

No início da intervenção proposta neste trabalho, a fala de algumas participantes sugere que o corpo gordo ainda se mantinha como um empecilho para novos relacionamentos ou mais envolvimento em situações sociais:

Hoje eu estou solteira, isso é outra coisa que a obesidade realmente atrapalha. Não me acho feia, mas também não me acho atraente com meu corpo. (P1).

Similarmente, a P10 relatou em sua entrevista de história de vida que sua percepção era que suas relações acabavam minando por causa da sua condição corporal:

Eu saio muito menos do que eu saia antes, é uma questão de aceitação, eu não me aceito dessa forma. Não tenho vontade de sair, de estar num grupo de amigos, de estar em determinados locais. É questão de se sentir bonita, atraente, de se sentir aceita talvez né. Eu não me sinto. (P10).

A mesma percepção se manteve na fala da P11. Diferentemente, a P2 relatou que não tinha dificuldade de relacionamentos e tinha uma extensa rede de amigos: "[...] eu tenho muitos amigos, muitos mesmo. E bons. Amigos mesmo, não é colega”.

Impactos do corpo gordo também podem ser vistos no estudo de Degher \& Hughes. ${ }^{41}$ Os autores analisaram qualitativamente como indivíduos com excesso de peso interagiam consigo e com outras pessoas, e quais as consequências dessas interações na sua identidade. Os participantes da pesquisa relataram que eram frequentemente confrontados com situações estressantes e emocionalmente desgastantes, e as contornavam respondendo negativamente às considerações feitas sobre sua condição física ou concordando com considerações negativas para serem mais bem aceitos. 
Parece plausível assumir que, para muitas das nossas participantes, sua condição corporal no início da intervenção era um fator limitante para que tivessem maior envolvimento social e afetivo. Um dos princípios do HAES ${ }^{\circledR}$ reconhece que a saúde e bem-estar são multidimensionais e incluem aspectos emocionais, físicos, espirituais e mentais, e que a experiência individual com o peso corporal e a saúde é parte de uma complexa interação de tais fatores. ${ }^{20}$ A partir deste princípio, ao longo da intervenção, tais aspectos foram respeitados e levados em conta na elaboração das estratégias de cuidado das participantes.

Entre as estratégias utilizadas nos atendimentos nutricionais, destaca-se o estabelecimento de metas. Embora este envolvesse majoritariamente aspectos relacionados à alimentação das participantes, não se limitava a essa esfera. Poderia incluir, por exemplo, indagações como: 1) Quem pode ajudar a participante em determinado aspecto?; 2) Quais aspectos da sua rotina podem ser mudados para que determinada meta seja mais facilmente praticada?; 3) Como a participante pode aumentar o cuidado de si mesma?

Nas oficinas filosóficas, foi possível destacar o tema de moralização do corpo como importante ferramenta para abranger e discutir experiências individuais com a condição corporal das participantes. Como reflexo, logo no início da intervenção, algumas participantes relataram que já se sentiam mais motivadas para tornar seu dia a dia mais ativo, como destacado nas seguintes falas:

[...] Eu ficava só em casa, então eu tenho que sair segunda, quarta e sexta para vir aqui. [...] Então é um preparo, é uma coisa diferente, é uma coisa que eu gosto, me sinto bem. Eles [familiares] também acham que eu melhorei muito, de humor, de tudo. (P6).

[...] Eles [familiares] estão vendo que eu tô contente, que eu tô saindo mais, acho que eles estão felizes por mim. (P7).

Também é interessante notar uma mudança de atitude das participantes em relação a seus corpos. Em um primeiro momento, elas expressaram estar mais confortáveis com o ritmo atual de seus corpos e menos preocupadas com a perda de peso por si só, sugerindo uma mudança em relação a suas expectativas anteriores:

Talvez o meu organismo hoje trabalhe mais devagar e tudo bem. Eu só tenho o cuidado de agora de não falar "ah, não deu certo hoje então já era". (P10).

Na metade da intervenção, essa percepção se manteve vigente:

[...] o que ficou mais forte é: tudo bem você estar numa situação corporal que você não está aceitando, mas isso não é o fim do mundo. E eu quero mudar, mas eu também não preciso ser neurótica, eu posso me aceitar do jeito que eu sou enquanto eu tô alcançando aquilo que eu quero. (P7). 
No último grupo focal conduzido, ideias nesse sentido também se destacaram, como ilustrado na fala da P9:

Antigamente eu olhava e eu me sentia gorda, me incomodava. Eu não emagreci tanto, mas eu me sinto bem, eu me olho, eu gosto. Eu reaprendi a gostar de mim, a dar tempo pra mim. Isso foi muito bom.

A P10 relatou que ela estava "satisfeita com o processo" e disse que aprendeu a respeitar seu ritmo e a se respeitar:

Eu tenho que me respeitar e eu acho que a intervenção me ajudou a falar "você não tá satisfeita, mas não é por isso que você não fazer nada, não vai se cuidar". (P10).

A mesma participante relatou que estava descobrindo atributos positivos nela ("é um exercício de perceber coisas bonitas em mim"). As falas destacadas mostram um posicionamento ativo das participantes para buscar mudanças que faziam sentido para elas em diferentes momentos da intervenção, sugerindo que tais mudanças foram um movimento crescente e constante ao longo do acompanhamento. Essas falas também parecem ser diferentes daquelas relatadas no momento inicial da intervenção, nas quais o corpo gordo apareceu como ser algo que "atrapalhava" e tirava a vontade das participantes de procurar outras atividades e se relacionar com outras pessoas.

Tem-se debatido um possível "benefício" da estigmatização de pessoas gordas, já que esta poderia motivar a perda de peso e sua manutenção. ${ }^{42}$ Questionam-se fortemente os efeitos na saúde e os impactos éticos de tal abordagem. Como destacado no estudo de Sutin e Terracciano, ${ }^{39} \mathrm{a}$ discriminação do corpo se relacionou diretamente com o ganho de peso ou com a manutenção do corpo gordo. Ademais, de acordo com os relatos de nossas participantes, atitudes negativas sobre o corpo também pareceram engessá-las e impossibilitá-las de buscar atividades que as cativavam e de construir laços afetivos.

Entender sobre imagem corporal parece, assim, ser importante para especificar experiências pessoais, sociais e psicológicas de se ter um corpo gordo e também para se pensar em novas estratégias de cuidado para pessoas com tal condição corporal.

Opiniões sobre o próprio corpo e a docilizaçãodo corpo gordo

Durante as entrevistas individuais, algumas participantes relataram opiniões que outras pessoas expressavam sobre seus corpos. A P1 relatou que sua irmã insistia para que ela procurasse um tratamento médico: 
Eu lembro que minha irmã mais velha comentava comigo que eu precisava comer menos, que eu precisava emagrecer. Aos 16 anos, de tanto dela encher a paciência da minha mãe ela me levou num endocrinologista, e foi a primeira vez que eu comecei a fazer um tratamento.

A mesma participante relatou o atendimento de um médico, no qual ele expressava sua opinião sobre o corpo dela:

[...] Ele dizia assim para mim "hoje você tem 22 anos, você vai ver, quando você chegar aos 25 vai ser muito mais difícil de você perder peso", dai quando chegava aos 25 ele falava "quando você chegar aos 28 vai ser muito mais difícil", e depois "o dia em que você for mãe então, vai ser mais difícil ainda".

Apenas a P9 relatou uma experiência positiva em relação a seu corpo: "[...] Meu marido me adora, fala que ele gosta da gordinha, que ele não quer que eu emagreça muito”.

Impactos de estigmas sofridos por pessoas com corpos gordos também podem ser observados no estudo de Lewis et al. ${ }^{43}$ Os autores fizeram um estudo qualitativo no qual, por meio de entrevistas semiestruturadas, investigaram como adultos obesos descreviam os diferentes tipos de estigmas que haviam sofrido, como responderam ao mesmo e como esta vivência impactava em sua saúde e bem-estar. Uma participante relatou uma experiência de estigma no trabalho:

[...] meu gerente dizia que eu tinha que perder peso porque isso estava afetando meu trabalho. Eu trabalho criando sites para pessoas com deficiências físicas, meu peso é completamente irrelevante.

Outros participantes do estudo de Lewis et $a l .{ }^{43}$ relataram que, frequentemente, sentiam que não pertenciam a alguns lugares, como em lojas de roupas, nas quais relataram como os atendentes os faziam sentir envergonhados por simplesmente olhar itens da moda. Alguns participantes também relataram experiências constrangedoras em consultórios médicos:

Quando eu vou a consultórios médicos eu não consigo sentar na cadeira porque no momento em que eu sento, eu fico presa nelas. Isso é irritante e constrangedor.

Pode-se compreender tais reações frente ao corpo gordo quando retoma-se que em fins do século XVIII, o corpo passou a ser valorizado como força de produção, tornando-se foco de grande investimento. ${ }^{44}$ É nesse contexto que a ociosidade assume conotação negativa ${ }^{45}$ e o corpo se torna realidade biopolítica, agenciado pela medicina. ${ }^{46}$ Medicina esta que, segundo Foucault, ${ }^{46}$ volta-se à relação corpo/força de trabalho apenas em um último momento da constituição do poder médico, se configurando como estratégia biopolítica, entendendo esta como: "a maneira como 
se procurou, desde o século XVIII, racionalizar os problemas postos à prática governamental pelos fenômenos próprios de um conjunto de viventes constituídos em população: saúde, higiene, natalidade, longevidade, raças" (2008, p. $431^{47}$ ).

Uma vez que o corpo é entendido como agente de produtividade, o corpo gordo recebe representações sociais de lento, improdutivo, preguiçoso e pernicioso ${ }^{45}$ e passa a ser esquadrinhado pela medicina. Pesquisas como as de Cori, Petty \& Alvarenga ${ }^{48}$ e de Swift et al. ${ }^{49}$ mostram com bastante clareza atitudes discriminadoras da população em geral em relação a pessoas gordas, incluindo profissionais de saúde, como ressaltado nas falas acima. O primeiro estudo se propôs a identificar atitudes de nutricionistas em relação à obesidade. Os resultados mostraram que há estigmatização e preconceito importantes contra o obeso. Características citadas por esses profissionais incluíram: guloso (67,4\%), não atraente $(52,0 \%)$, desajeitado $(55,1 \%)$, sem determinação $(43,6 \%)$ e preguiçoso $(42,3 \%){ }^{48}$

Aliada ao capitalismo, a medicina possibilita maior exploração da força de trabalho e docilização dos corpos, tornando-os mais maleáveis, ${ }^{44}$ na busca de aumento de sua força útil por meio de exercícios, vigilância e inspeções. ${ }^{50}$ Sujeito às forças do discurso médico, o corpo fora trabalhado e submetido a uma relação de docilidade-utilidade, a qual Foucault ${ }^{51}$ denominou "disciplina”. Assim, como aponta Novaes, ${ }^{52}$ as mulheres livraram-se de seus espartilhos e passaram a ser contidas "na justeza das próprias medidas" (p. 39). Deste modo, o suplício do espartilho foi substituído pelo discurso médico, o qual, buscando garantir a saúde, submeteu o corpo a novos sacrifícios.

O corpo passou a ser atravessado pela ginástica e, curiosamente, o termo mais usado é "malhar", como se malha o ferro, (re)esculpindo, consertando, modificando cada parte do corpo. ${ }^{44}$ Tal construção incorpora conotações simbólicas de sucesso, autocontrole, classe e competência à imagem corporal ideal: magro, jovem, branco e de classe média. A seu negativo, são incorporados aspectos como falta de força de vontade, preguiça e fraqueza. ${ }^{3}$ Nesse contexto que vincula magreza a uma virtude moral - como exposto na fala da P8 "tem que tomar vergonha na cara” - Dirce de Sá Freire ${ }^{53}$ aponta para a substituição da necessidade de confissão dos pecados pelo ato de subir na balança, a prestar contas ao social.

Como reflexo das constantes pressões acerca do corpo, as participantes do presente estudo relataram se engajar em diferentes estratégias para perder peso, como contratar um personal trainer, fazer acompanhamento terapêutico e médico, propor-se a fazer atividades físicas sem acompanhamento profissional e em excesso, tomar medicamentos para emagrecer ese engajar em diferentes dietas. Sobre esta última estratégia, as tentativas relatadas por elas foram diversas:

[...] já fiz a dieta macrobiótica, já fiz aquela dieta para desintoxicar, eram oito dias só comendo arroz integral, já comi alho também, todo dia eu comia um pedacinho de alho [...] (P2).

[...] já comi farinha de maracujá, a farinha do feijão, e tomei o chá para emagrecer. (P4). 
Algumas participantes relataram ter se engajado em dietas comerciais. A P12, por exemplo, relatou que fez o "Vigilantes do Peso", mas ela não se adaptou com as porções e quantidades propostas; a P13 relatou que sua última tentativa foi a dieta de Atkins; e a P3 tomou por muitos anos shakes de emagrecimento. Vê-se que a dor e o sacrifício do exercício físico não apenas modelam o corpo, mas o caráter, sendo então aceito, como a P12 apresentou: "Eu nunca tinha feito atividade física e eu achei que não é a pior coisa do mundo. Pode não ser a melhor, mas eu preciso dela”.

A construção simbólica e social em torno do corpo cria uma relação de poder sobre tal corpo, que pode ser classificado, nomeado e tipificado. Contudo, para Foucault, este poder é difuso e não repressivo, produzido em todos os níveis e relações. ${ }^{45,54}$

As falas destacadas no início desta seção indicam a apropriação do discurso médico sobre o corpo no espaço familiar e a relação com moralidade (aqui associada ao castigo apenas àquele que precisa emagrecer). A mesma ideia se repetiu quando as participantes já estavam engajadas na intervenção, quando elas levantam expectativas de terceiros sobre seus corpos. Por exemplo, para a P3, seus familiares apresentaram uma postura de policiamento e crítica, cobravam a perda de peso e não apoiavam as mudanças que ela estava se dispondo a fazer:

Eles falam assim "quem tá de regime é você, quem tem que emagrecer é você. Você não pode castigar a gente pra comer coisa de regime porque nós não precisamos disso".

Este exercício de poder contínuo, que dociliza os corpos, também se mostra internalizado pelas próprias participantes, como apontam as falas das P8 e P10:

[...] vi que a gente mesmo fala mal da gente porque nós estamos acima do peso ou obesas. (P8).

[...] eu tenho noção de que eu quero, preciso e que eu vou me sentir mais feliz se eu perder mais peso. (P10).

No início da intervenção, algumas participantes levantaram ter uma visão diferente do corpo quando se viam em fotos ou suas imagens em espelhos:

[...] eu olho as fotos e falo "nossa, como pode, que coisa horrorosa" [...]. Hoje eu estou com 112 quilos, mas eu não tenho essa imagem do meu corpo. Eu me olho no espelho e eu não acho que eu estou igual à moça da foto (P1).

Complementarmente, todas as participantes, na fase inicial da intervenção, relataram sentimentos negativos em relação a seus corpos, como estes: "Não estou satisfeita" (P1); "Não estou bem com meu corpo" (P10 e P12); "Com meu corpo acho que está ruim” (P11); e "Com meu corpo me sinto mal, mal pra caramba" (P14). 
Algumas participantes dividiram sobre como relacionavam sua condição corporal às mudanças na sua vida. A P10 relatou o seguinte:

Eu fiz uma bateria de exames para ver se tinha alguma coisa a ver com a tireoide e não tinha [...]. Isso me despreocupou, mas me frustrou também, porque significava que era eu mesma, que não era o meu organismo.

A P14 relatou que relacionava sua condição corporal com uma "safadeza" da parte dela: "[...] é mais safadeza, está tudo no psicológico. Eu não tenho fome assim, eu como porque eu como". E a P13 falou que já havia tentado "de tudo", mas completou: "[...] de tudo entre aspas, porque se eu tentasse de tudo teria conseguido".

Destaca-se, nessas falas, que a culpa pela "falha" no processo de emagrecimento é sempre atribuída a uma falha da participante, e não da estratégia escolhida, que, infelizmente, não chega a ser questionada. Outras respostas sobre a que relacionavam seu peso atual incluíram aspectos emocionais, como a ansiedade (P1, P2, P9, P12) e ter se deixado de lado enquanto cuidava de outras pessoas $(\mathrm{P} 10)$.

No intuito de questionar e provocar discussões acerca da construção social do corpo gordo, esta intervenção pareceu possibilitar maior apropriação e afirmação do corpo próprio. Nosso objetivo com a intervenção proposta era promover mudanças considerando o peso atual das participantes e que não iríamos prescrever uma dieta ou qualquer outra prescrição para elas. Ancorava-nos no princípio do HAES®, que afirma que o movimento em direção a um estilo de vida mais saudável vai, com o tempo, resultar num peso corporal mais adequado (quando e se necessário).

Algumas participantes levantaram ter sido um alívio que a intervenção teria uma proposta sem prescrição de dietas e que não tinham expectativas em relação a elas ("Eu fiquei aliviada, falei 'graças a Deus ninguém tem um grande plano sobre a minha pessoa”' - P10). Já no primeiro grupo focal, conduzido no início da intervenção, algumas participantes mostraram uma mudança em relação a expectativas pregressas. Elas destacam que, embora não tivessem tido grande perda de peso, se sentiam mais motivadas para dar continuidade à intervenção:

[...] eu não vi na balança uma grande diferença, mas em compensação eu percebo que eu tenho mais coragem, mais vontade de continuar fazendo. (P13).

As participantes também pareceram ter uma expectativa mais real em relação a seus corpos, o que também pareceu ter impactado na motivação delas para permanecer na intervenção. Passados alguns meses deintervenção, as participantes levantaram que a imagem do espelho ainda não condizia com a imagem que elas tinham do corpo delas, como ressaltado na seguinte fala: 
[...] quando eu vejo uma foto, um vídeo que eu falo gente, eu não acredito que eu tô desse tamanho, porque lá no espelho não parece, parece que eu sou menor. (P5).

Ainda assim, no último grupo focal, as participantes levantaram que, embora não estivessem completamente satisfeitas com sua condição corporal atual, elas de fato mudaram alguns dos paradigmas anteriores e amadureceram suas opiniões:

[...] eu estou satisfeita com o processo porque eu sei que é um processo mais lento. Eu tenho que respeitar o meu ritmo, não falar "ah, já que eu sou assim então deixa" (P10).

Durante a intervenção, discussões envolvendo o tema da imagem corporal foram abordadas nas três esferas envolvidas (aconselhamento nutricional, atividade física e filosofia). Parece que uma das contribuições de se abordar tal questão foi ajudar as participantes a entenderem como o processo de construção da imagem corporal se dá, o que as empodera para lidar com as diversas expectativas acerca do corpo e também as auxilia a ficar mais confortáveis com sua condição corporal atual.

\section{Movimentação do corpo}

Acerca da prática de atividades físicas, algumas participantes relataram ter sido crianças ou adolescentes bastante ativas, mostrando-se engajadas com atividades esportivas na escola, no clube ou até mesmo como parte de brincadeiras cotidianas da infância: "Quando eu era novinha adorava correr, ninguém me catava, eu adorava correr [...]" (P2); ou "até os 16 anos eu jogava, então assim, eu vivia no clube, eu ia pra escola, ia pro clube e voltava à noite" (P9).

Com o passar do tempo, o aumento de responsabilidades fez com que esses momentos perdessem espaço. Elas relataram atividades que iniciaram e gostavam, porém não deram continuidade, como dança, pilates, andar em parques, academia. No entanto, no início da intervenção, eram poucas as participantes que relataram se engajar em atividades físicas rotineiramente, além daquelas propostas na pesquisa.

A P2 relatou, por exemplo, que sua movimentação corporal fora das atividades em quadra envolvia seus afazeres domésticos. A P1 relatou que gostava muito de dança, mas com o passar do tempo, perdeu o prazer em fazer esta atividade e, consequentemente, perdeu o interesse em ir. Já a P8 relatou que, embora ela gostasse muito de dançar, destacou sua condição corporal como motivo para descontinuar a atividade: 
[...] eu tinha mais habilidade para dançar. Hoje eu não tenho nenhuma, nenhuma, e isso me pesa. Barriga me pesa, a perna me pesa, eu não tenho muito fôlego, essas coisas assim eu não tenho mais.

Além disso, experiências de julgamento e crítica de profissionais pareceram ter desencorajado a adesão das participantes a novas atividades. A P8 destacou uma percepção acerca do ambiente de academias:

[...] quando você vai numa academia, aquele povo não é carinhoso com você, já olha assim "aquela gorda sabe, não consegue segurar nem três quilos".

Esta ideia central destacou uma experiência de julgamento e crítica acerca da condição corporal e capacidade física das participantes:

Eu comecei a fazer ginástica e a professora ela ficava fazendo comentários do tipo é... Que eu não conseguia alcançar, que eu era muito lenta... Meio que o trauma que eu já tenho disso aumentou entendeu? (P3).

Alvarado, Guell e Murphy ${ }^{55}$ realizaram estudo qualitativo para identificar barreiras para a atividade física e explorar aspectos que facilitavam sua prática. A amostra envolveu mulheres com sobrepeso e obesidade, e com elas foram feitas entrevistas individuais semiestruturadas. Dentre as barreiras levantadas pelas participantes, destacaram-se aspectos sociais, estruturais e relacionados à saúde. Os primeiros se relacionaram a normas de gênero e expectativas associadas. Por exemplo, as mulheres relataram que tendiam a ser mais ativas com pares do sexo feminino e que a possibilidade de estarem ativas também competia com responsabilidades familiares. As barreiras estruturais citadas incluíram a dificuldade de deslocamento entre um local e outro, o espaço limitado para atividade física em casa e a possibilidade limitada de acesso a espaços pagos de atividade física. Em contrapartida, algumas atividades destacadas como sendo exequíveis e de sucesso incluíram caminhar e se engajar em grupos de atividade física de baixo custo.

Toft \& Uhrenfeld $^{56}$ fizeram uma revisão de literatura qualitativa para identificar fatores facilitadores e limitantes para a prática de atividade física a partir de experiências de adultos obesos grau III. Oito estudos foram incluídos, e em todos se observou que as experiências de perda e ganho de peso corporal tinham impactos nos participantes. Com frequência, a atividade física foi impulsionada pela perda de peso corporal ou por esta ser uma ferramenta para o gerenciamento do peso corporal.

Por exemplo, ter o peso corporal aferido foi mencionado como uma estratégia necessária para manter os participantes engajados nas atividades físicas, e também se relacionou com a percepção de sucesso ou insucesso do participante. ${ }^{56}$ Quando a perda de peso era pequena ou muito 
baixa, percebeu-se uma atitude negativa dos participantes para dar continuidade às atividades. Ilustrativamente, em um dos estudos, foi relatado: "você não consegue permanecer engajado nas atividades físicas se você não vê resultados".

A expectativa de se alcançar determinado peso corporal se relacionou não apenas com um padrão corporal esperado, mas também com mais liberdade, novas possibilidades e se tornar mais atraente. No entanto, o foco excessivo no peso corporal também levantou percepções negativas de alguns participantes, como, por exemplo ${ }^{56}$ : "ter as medidas e o peso corporais aferidos e ouvir que você é culpado não foi bom”.

Outro fator levantado como empecilho para a prática de atividade física foi a autonomia, como destacado na seguinte fala ${ }^{56}$ : "me dê um personal trainer que me tire da cama todos os dias e me faça me exercitar que, sim, eu perderia peso".

A ênfase das atividades físicas oferecidas durante nossa intervenção foi na promoção da saúde e no movimento do corpo, sem foco na intensidade, estrutura e duração das atividades, nem no peso corporal. Os educadores físicos foram preparados para lidar com sentimentos das participantes - como medo, desapontamento e vergonha - que possam surgir nas atividades físicas de maneira empática e colaborativa. Antes de iniciar as atividades físicas, e ao longo da intervenção, as participantes puderam expressar sua opinião acerca de que tipo de atividades físicas elas consideravam que seriam mais agradáveis para realizarem. Essa postura empática dos educadores físicos pareceu, por si só, ser fator determinante para a adesão das participantes às atividades em quadra, como destacado na fala da P13:

[...] eu acho que eles [educadores físicos] são a base, eles estão sempre com a gente ali e dá muita energia pra gente. Qualquer lugar que você passa eles te cumprimentam... Eu acho que isso é um carinho especial do programa assim em geral.

A maneira como as atividades físicas foram propostas também pareceu ter beneficiado as participantes:

Minha maior dificuldade pra fazer atividade física em outros lugares era a vergonha do meu corpo e aqui eu não tenho vergonha porque nós estamos praticamente todas no mesmo patamar. (P3).

Como resultado, com o passar da intervenção, as participantes trouxeram falas que pareceram mostrar que a movimentação do corpo se tornou mais presente na vida delas e, mais importante, se tornou algo prazeroso e sustentável. No último grupo focal, as participantes se autoavaliaram e avaliaram como estariam dali alguns anos. Elas relataram que se viam mais envolvidas com atividades físicas, aproveitando espaços da cidade: 
[...] Me vejo saindo mais, você tem biblioteca, museu, você pode ir andando e voltar andando, tem um monte de parques. Então eu me vejo aproveitando mais o que a cidade oferece, que também proporciona melhor qualidade de vida. (P10).

As participantes também destacaram benefícios da movimentação corporal para além da perda de peso, como melhora na resistência física, melhora no raciocínio (P1, P2, P3, P9, P10, P12), mais agilidade (P2, P8, P9, P10, P12, P13, P14), melhora de quadros de doenças crônicas e diminuição do uso de remédios (P9, P10, P11, P12, P13, P14), diminuição do estresse e melhora da qualidade do sono (P8, P10, P11). Parece que as atividades físicas como propostas na nossa intervenção proporcionaram aspectos facilitadores para a inclusão de práticas corporais no dia a dia das participantes.

Diferentemente das barreiras observadas na revisão de literatura de Toft \& Uhrenfeld, ${ }^{56} \mathrm{O}$ peso corporal não foi fator determinante para a adesão de nossas participantes às atividades físicas. Pelo contrário, parece que o distanciamento dessa expectativa, como explorado nos eixos interpretativos anteriores, tornou as participantes mais engajadas nas atividades e lhes permitiu destacar outros ganhos como sendo de sucesso. Ademais, elas pareceram se mostrar autônomas para inserir diferentes atividades físicas no seu dia a dia, o que provavelmente reflete a diferença entre esta abordagem eoutra mais prescritiva, verticalizada e passiva.

É evidente que a movimentação corporal é vital para possibilitar a potencialização da saúde e da qualidade de vida. Sabe-se que é importante ser ativo, mas parece ser importante olhar como se aborda e como se propõe essa movimentação corporal. Estratégias tradicionalmente propostas - muitas vezes voltadas unicamente para o gasto energético e a performance - parecem não ter surtido efeitos sustentáveis. Em contrapartida, parece que propor atividades que estimulam a movimentação corporal e que resgatam o prazer de movimentar o corpo é mais efetivo e inclusive estimula a inserção de novas atividades na rotina, como foi visto com nosso grupo de mulheres.

\section{Conclusão}

Objetivou-se analisar qualitativamente a percepção de mulheres obesas sobre ter um corpo gordo e como elas vivenciaram e foram impactadas por essa condição corporal antes e depois de participarem de uma intervenção não prescritiva, multidisciplinar e baseada na abordagem "Health atEverySize ${ }^{\circledast "}$.

As participantes relataram que o corpo gordo teve um impacto em sua personalidade, tornando-as menos suscetíveis a interações sociais e relacionamentos em ciclos de vida anteriores, e também já na vida adulta. A partir dos estímulos da intervenção, elas relataram se mostrar mais 
motivadas a construir novos relacionamentos afetivos. Relataram, ainda, experiências de assédio moral e discriminação sobre seus corpos, como médicos e familiares, o que as pressionou a buscar pormaneiras diversas de perder peso.

Em contrapartida, as diferentes estratégias utilizadas na intervenção, de acordo com os discursos das participantes, as tornaram mais empoderadas para lidar com expectativas acerca de seus corpos, auxiliando-as a se sentir mais confortáveis com sua condição corporal atual. Finalmente, enquanto que no início da intervenção as participantes relataram experiências negativas associadas à prática de atividades físicas e se mostravam resistentes às mesmas, ao final do período de acompanhamento se mostraram motivadas a inserir mais atividades físicas em suas rotinas e relataram ganhos fisiológicos e psicológicos advindos do aumento da movimentação corporal.

Viu-se que houve uma construção simbólica e social sobre o corpo, estabelecendo uma relação de poder sobre o mesmo. Essa construção é influenciada por diversos discursos, que, por sua vez, contribuem para a docilização do corpo. Parece possível concluir que entender o corpo gordo estritamente por óticas biológicas tem se mostrado cada vez mais uma estratégia limitante e reducionista, restringindo as possibilidades de cuidado na área da saúde.

A abordagem HAES ${ }^{\circledR}$ supera tal limitação, uma vez que tem como princípio encorajar a construção de uma imagem corporal positiva. No entanto, estudos que se basearam na abordagem não reportaram avaliar a percepção dos participantes sobre sua condição corporal, reduzindo a possibilidade de observar a potencialidade de tal estratégia. No presente estudo, vimos que encorajar este princípio parece ser uma possibilidade de questionar a moralização do corpo gordo, contribuir para a construção de uma imagem corporal mais positiva e superar representações sociais usualmente associadas a tal condição corporal (tais como lentidão, improdutividade, preguiça).

Em última análise, parece que o formato proposto na presente intervenção não reforçou o mecanismo de docilização dos corpos gordos e contribuiu para o empoderamento de pessoas que outrora vivenciaram tal mecanismo. Avançar para um entendimento mais amplo dessa condição corporal, como destacado neste trabalho, parece contribuir para a construção de novas possibilidades de intervenções e levar à mudança de pessoas que têm um corpo gordo.

\section{Agradecimentos}

Os autores agradecem às participantes, pela confiança e colaboração durante o estudo, e às bolsas cedidas pela Fundação de Amparo à Pesquisa do Estado de São Paulo (FAPESP - números 2012/12035-0 e 2015/12235-8), ao CNPq (números 309121/2012-4 e 311357/2015-6) e à CAPES. 


\section{Referências}

1. Chapman GE. From dieting to healthy eating: an exploration of shifting constructions of eating for weight control. In: Sobal J, Maurer D. Interpreting weight: the social management of fatness and thinness. New York: Aldine de Gruyter; 1999. p. 73-87.

2. Sobal J. Social and cultural influences on obesity. In: Bjorntorp P, editer. International textbook of obesity. New York: John Wiley \& Sons; 2001. p. 305-322.

3. Vasconcelos NA, Sudo I, Sudo N. Um peso na alma: corpo gordo e mídia. Revista Mal-Estar e Subjetividade 2005; 4:65-93.

4. Stearns PN. The turning point. In: Stearns PN, organizer. Fat bodies: bodies and beauty in the modern west. New York: New York University Press; 2002. p. 3-24.

5. Scagliusi FB, Lourenço BH. A ditadura da beleza e suas consequências no discurso nutricional. In: Alvarenga M, Scagliusi FB, Philippi ST, organizadoras. Nutrição e transtornos alimentares: avaliação e tratamento. Barueri: Manole; 2011. p. 59-83.

6. Bell K, McNaughton D. Feminism and the invisible fat man. Body \& Society 2007; 13(1):107-131.

7. Santolin CB, Rigo LC O nascimento do discurso patologizante da obesidade. Movimento: Revista da Escola de Educação Física da UFRGS 2015; 21(1):81-94.

8. Birman J. A biopolítica na genealogia da psicanálise: da salvação à cura. História, Ciências, Saúde 2007; 14(2):529-548.

9. Canguilhem G. O normal e o patológico. Rio de Janeiro: Forense; 1995.

10. Poulain JP. Sociologie de l'obésité. France: Puf; 2009.

11. Vester K. Regime change: gender, class, and the invention of dieting in post-bellum America. Journal of Social History 2010; 44(1):39-70.

12. Fischler C. Food, self and identity. Social Science Info 1988; 27:275-92.

13. Kessler DA. The end of overeating: taking control of the insatiable American Appetite. New York: Rodale Books; 2009.

14. Sobal J, Maurer D. Interpreting weight: the social management of fatness and thinness. New York: Aldine de Gruyter; 1999.

15. Yaemsiri S, Slining MM, Agarwal SK. Perceived weight status, overweight diagnosis, and weight control among US adults: the NHANES 2003-2008 Study. Int. J. Obes. 2011; 35(8):1063-1070.

16. Montani J-P, Schutz Y, Dulloo AG. Dieting and weight cycling as risk factors for cardiometabolic diseases: who is really at risk? Obes. Rev. 2015; 16 (Supl. 1):7-8.

17. Curioni CC, Lourenço PM. Long-term weight loss after diet and exercise: a systematic review. Int. J. Obes. 2005; 29(10):1168-1174.

18. Rolland C, Johnston KL, Lula S, Macdonald I, Broom J. Long-term weight loss maintenance and management following a VLCD: a 3 -year outcome. Int. J. Clin. Pract. 2014; 68(3):379-387. 
19. Siahpush M, Tibbits M, Shaikh RA, Singh GA, Kessler AS, Huang TT-K. Dieting increases the likelihood of subsequent obesity and BMI gain: results from a prospective study of an Australian national sample. Int. J. Behav. Med. 2015; 22(5):662-671.

20. Association for Size Diversity and Health. ASDAH [Internet]. [acesso em: 15 abr. 2016]. Disponível em: https://www.sizediversityandhealth.org/

21. Provencher V, Bégin C, Tremblay A, Mongeau L, Corneau L, Dodin S, et al. Health at every size and eating behaviors: 1 -year follow-up results of a size acceptance intervention. J. Am. Diet. Assoc 2009; 109(11):1854-1861.

22. Gagnon-Girouard MP, Provencher CBG, Tremblay A, Mongeau L, Boivin S, Lemieux S. Psychological impact of a "Health-at-Every-Size" intervention on weight-preoccupied overweight/obese women. J. Obes. 2010; 1-12.

23. Borkoles E, Carroll S, Clough P, Polmand RCJ. Effect of a non-dieting lifestyle randomised control trial on psychological well-being and weight management in morbidly obese pre-menopausal women. Maturitas 2016; 83:51-58.

24. Bacon L, Stern JS, Van Loan MD, Nancy L, Keim NL. Size Acceptance and intuitive eating improve health for obese, female chronic dieters. J. Am. Diet. Assoc. 2005; 105(6):929-936.

25. Leblanc V, Provencher V, Bégin C, Corneau L, Tremblay A, Lemieux S. Impact of a health at every size intervention on changes in dietary intakes and eating patterns in premenopausal overweight women: results of a randomized trial. Clin. Nutr. 2012; 31:481-48.

26. Humphrey L, Clifford D, Morris MY. Health at Every Size college course reduces dieting behaviors and improves intuitive eating, body esteem, and anti-fat attitudes. J. Nutr. Educ. Behav. 2015; 47(4):354-360.

27. Dalen J, Smith BW, Shelley BM, Sloan AL, Leahigh L, Begay D. Pilot study: Mindful Eating and Living (MEAL): weight, eating behavior, and psychological outcomes associated with a mindfulnessbased intervention for people with obesity. Complementar Ther. Med. 2010; 18(6):260-264.

28. Bacon L, Aphramor L. Weight science: evaluating the evidence for a paradigm shift. Nutr. J. 2011; 10:9-21.

29. Ulian MD, Gualano B, Benatti FB, Campos-Ferraz PL, Roble OJ, Modesto BT, et al. "Now I can do better": a study of obese women's experiences following a non-prescriptive nutritional intervention. Clin. Med. Insights: Women's Health 2015; 8:13-24.

30. Ulian MD, Benatti FB, Campos-Ferraz PL, Roble OJ, Unsain RF, Sato PM, et al. The effects of a 'Health at Every Size' based approach in obese women: a pilot-trial of the 'Health and Wellness in Obesity’ study. Front. Nutr. 2015; 2(34):1-12.

31. Ulian MD, Scagliusi FB, Sato PM, Modesto BT, Benatti FB, Gualano B, et al. Saúde e bem-estar na obesidade: paradoxo ou possibilidade? Rev. Cul. Ext. 2015; (14):123-131.

32. Ulian MD, Gualano B, Benatti FB, Roble OJ, Campos-Ferraz PL, Unsain RF, et al. Strategies for the care of obese: a non-prescriptive nutritional perspective. In: Entrena-Duran F, organizer. Food production and eating habits around the world: a multidisciplinary approach. New York: Nova Publishers; 2015. p. 73-88. 
33. Motta DG. Aconselhamento nutricional. In: Motta DG, organizador. Educação nutricional \& Diabetes tipo 2. Piracicaba: Jacintha; 2009. p. 27-33.

34. Lima A, Gualda DMR. História oral de vida: buscando o significado da hemodiálise para o paciente renal crônico. Rev. Esc. Enferm. USP 2001; 35(3):235-241.

35. Paulilo M. A pesquisa qualitativa e a história de vida. Serviço Social \& Sociedade 1999; 2:135-48.

36. Thompson P. A voz do passado: história oral. Rio de Janeiro: Paz e Terra; 1992.

37. Schwartz MB, Brownell KD. Obesity and body image. Body Image 2004; 1:43-56.

38. Goffman E. Stigma. Notes on the management of spoiled identity. London: Penguin; 1968.

39. Sutin AR, Terracciano A. Perceived weight discrimination and obesity. PLoS ONE 2013; 8(7):e70048.

40. Puhl R, Peterson J, Luedicke J. Fighting obesity or obese persons? Public perceptions of obesityrelated health messages. Int. J. Obes. 2012; 37(6):774-82.

41. Degher D, Hughes G. The adoption and management of a "fat" identity. In: Sobal J, Maurer D, organizers. Interpreting weight: the social management of fatness and thinness. New York: Aldine de Gruyter; 1999. p. 11-27.

42. Bayer, R. Stigma and the ethics of public health: not can we but should we. Soc. Sci. Med. 2008; 67(3):463-472.

43. Lewis S, Thomas SL, Hyde J, Castle D, Komesaroff PA, Warwick Blood R. "I don't eat a hamburger and large chips every day!": a qualitative study of the impact of public health messages about obesity on obese adults. BMC Public Health 2010; 10:309.

44. Araújo EMN, Meneses JR. Histórias do corpo e do feminino no Brasil do tempo presente. Anais do XXVI Simpósio Nacional de História; jul. 2011; São Paulo: ANPUH-SP, 2011; 1:1-12.

45. Silva TMG. O corpo feminino sob tirania na pós-modernidade. Rev. Unifarmma 2013; 12(1):41-54.

46. Foucault M. Microfísica do poder. 8 ed. Rio de Janeiro: Graal; 1989.

47. Foucault M. Nascimento da biopolítica: curso dado no Collège de France (1978-1979). São Paulo: Martins Fontes; 2008.

48. Cori GC, Petty MLB, Alvarenga MS. Atitudes de nutricionistas em relação a indivíduos obesos: um estudo exploratório. Ciênc. Saúde Coletiva 2015; 20(2):565-576.

49. Swift JA, Hanlon S, El-Redy L, Puhl RM, Glazebrook C. Weight bias among UK trainee dietitians, doctors, nurses and nutritionists. J. Hum. Nutr. Diet. 2013; 26:395-402.

50. Nespoli N, Novaes JV, Rosa CM. O corpo na cultura: obesidade como doença, biopolítica e normalização. Desafios: Revista Interdisciplinar da Universidade Federal de Tocantins 2015; 1:149-168.

51. Foucault M. Vigiar e punir: nascimento da prisão. 14 ed. Vozes; 1996.

52. Novaes JV. Com que corpo eu vou? Sociabilidade e usos do corpo nas mulheres das camadas altas e populares. Rio de Janeiro: Ed. PUC/Pallas; 2010. 
53. Freire DS. Com açúcar, sem afeto. In: Del Priore M, Amantino M, organizadores. História do corpo no Brasil. São Paulo: Editora Unesp; 2011. p. 453-476.

54. Berg R. Medicina, Freud e obesidade: diálogos multidisciplinares sob a perspectiva de Foucault. Ágora: Estudos em Teoria Psicanalítica 2011; 14(2):183-196.

55. Alvarado M, Guell C, Murphy M. Barriers and facilitators to physical activity amongst overweight and obese women in the Caribbean: a qualitative study. International Journal of Behavioral Nutrition and Physical Activity 2015; 12:97.

56. Toft BS, Uhrenfeldt L. The lived experiences of being physically active when morbidly obese: a qualitative systematic review. Int. J. Qual. Stud. Health Well-being 2015, 10: 28577.

Recebido: $15 / 4 / 2016$

Revisado: 03/8/2016

Aceito: 17/8/2016 